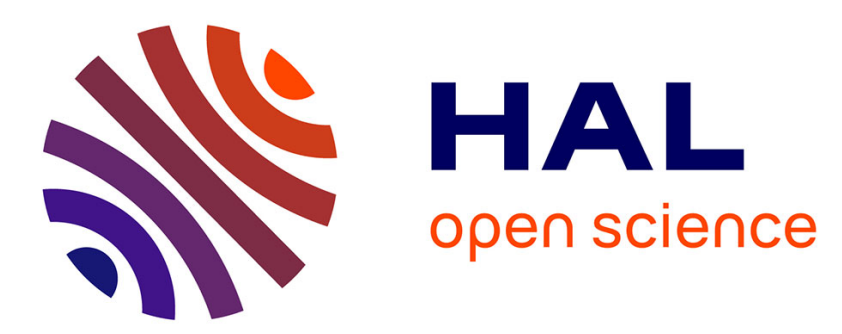

\title{
Design of a new coplanar isolator made from YIG film operating in the $\mathrm{X}$-frequency band
}

S. Kirouane, D. Vincent, E. Vernet, O. Zahwe, B. Payet-Gervy, A. Chaabi

\section{To cite this version:}

S. Kirouane, D. Vincent, E. Vernet, O. Zahwe, B. Payet-Gervy, et al.. Design of a new coplanar isolator made from YIG film operating in the X-frequency band. European Physical Journal: Applied Physics, 2012, 57 (1), 10.1051/epjap/2011110091 . hal-00758054

\section{HAL Id: hal-00758054 https://hal.science/hal-00758054}

Submitted on 28 Nov 2012

HAL is a multi-disciplinary open access archive for the deposit and dissemination of scientific research documents, whether they are published or not. The documents may come from teaching and research institutions in France or abroad, or from public or private research centers.
L'archive ouverte pluridisciplinaire HAL, est destinée au dépôt et à la diffusion de documents scientifiques de niveau recherche, publiés ou non, émanant des établissements d'enseignement et de recherche français ou étrangers, des laboratoires publics ou privés. 


\title{
Design of a New Coplanar Isolator made from YIG Film
}

\section{Operating in the X-frequency band .}

\author{
S. Kirouane ${ }^{1}$, D. Vincent ${ }^{1}$, E. Vernet ${ }^{1}$,O. Zahwe ${ }^{1}$, B. Payet-Gervy ${ }^{1}$, A. Chaabi ${ }^{2}$ \\ 1 Université de Lyon, F-42023, Saint-Etienne, France \\ Université de Saint-Etienne, Jean Monnet, F-42000, Saint-Etienne, France \\ LT2C, F-42000, Saint-Etienne, France. email : vincentd@univ-st-etienne.fr \\ 2 Laboratoire des semi-conducteurs et des hyperfrquences, Universit Mentouri de Constantine, Route Ain el Bey
}

Received: / Revised version:

\begin{abstract}
The miniaturization of devices and the increase of operating frequencies are two important issues for communication system development. This requires a high degree of integration, higher performance and lower cost. Isolator is an important non-reciprocal passive component for source protection. In most cases, the non-reciprocal effect is based on field displacement phenomenon induced by a magnetized ferrite material. In this paper we propose a new design of a coplanar isolator based on field displacement, composed of a non symmetrical coplanar transmission line, made from a ferrite layer and ground plane below. Simulations were performed using HFSS software. Measurements were made on a first $1000 \mu m$-thick YIG film sample giving $1 d B$ of insertion losses and $17 d B$ isolation and on a second sample made from a $150 \mu m$-thick YIG ferrite sample giving an insertion loss lower than $2 d B$. Interesting applications of this isolator structure are considered.
\end{abstract}

PACS. PACS 80 Interdisciplinary Physics and Related Areas of Science and Technology

\section{Introduction}

Considerable advances have been made towards miniaturization and performance optimization of existing structures that can be used in electronic integration RF sys- tems. Isolators, among non-reciprocal components, are useful for applications in RF frequency circuits [1] [2]. The ferrite properties in microwave range are used to create non-reciprocal propagation. The first isolators were made from waveguide loaded by a ferrite slab, but their size 
made them incompatible with integration. These devices are only used for high power . Other types of isolators based on field displacement phenomenon in microstrip technology [3] can be used in small size and low power circuits. The first coplanar isolator was proposed by Wen [4]. In the latter work, the non-reciprocal effect was based on the gyromagnetic resonance, and even if a high isolation seemed to have been reached, insertion loss was still too high. In this paper, a novel ferrite coplanar isolator based on field displacement combined to magnetostatic waves is presented. Two isolator samples were made from two ferrite thicknesses. The first one uses a $1000 \mu m$-thick ferrite substrate, the second, a $150 \mu m$-thick ferrite layer deposited on an alumina substrate. Some special characteristics of this coplanar isolator study are presented with the aim to reach specifications recommended for RF industrial RF components. Many parameters, size and geometrical parameters, physical properties of the ferrite layer..., have to be found to optimize the component performance. This article aimed at showing the feasibility of a small coplanar isolator fabrication using ferrite films. The manufacturing process was developed in LT2C laboratory.

\section{Numerical Study}

The choice of magnetic material has focused on the YIG due to its very good properties in microwave range ( magnetic loss, high resistivity...). Therefore, this is material widely used in X- band for non-reciprocal components. The following physical parameters are used by the simulation software (HFSS):
- Dielectric constant $\epsilon=15.3$

- Magnetization saturation $M_{s}=1780$ Gauss

- Ferromagnetic linewidth $\Delta H=100$ Oe

- Dielectric loss tangent $\tan \delta=2.10^{-4}$

- Applied field (internal field for HFSS): $H_{0}=222.816$ $\mathrm{kA} / \mathrm{m})$.

The ferrite is supposed to be saturated and the internal bias field to be uniform. In this analysis, the permeability tensor for a soft saturated ferrite is given by [5]:

$$
\begin{aligned}
& \overline{\bar{\mu}}=\mu_{0}\left[\begin{array}{ccc}
\mu & -j \kappa & 0 \\
j \kappa & \mu & 0 \\
0 & 0 & 1
\end{array}\right] \\
& \mu=\mu^{\prime}-j \mu^{\prime \prime}=1+\frac{\left(\omega_{0}+j \alpha \omega\right) \omega_{m}}{\left(\omega_{0}+j \alpha \omega\right)^{2}-\omega^{2}} \\
& \kappa=\kappa^{\prime}-j \kappa^{\prime \prime}=\frac{\omega \omega_{m}}{\left(\omega_{0}+j \alpha \omega\right)^{2}-\omega^{2}}
\end{aligned}
$$

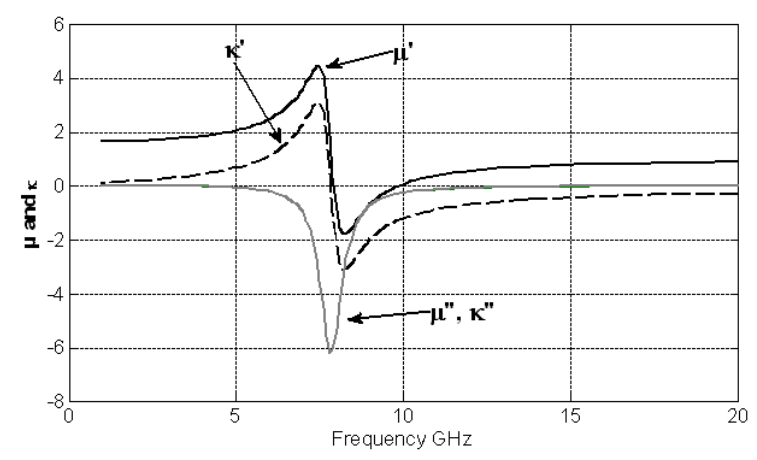

Fig. 1. Ferromagnetic resonance: real and imaginary parts of the elements of the permeability tensor versus frequency (223 $\mathrm{kA} / \mathrm{m}$ applied field).

where $\omega_{0}=\gamma H_{i}$ is the gyromagnetic resonance frequency, $\omega_{m}=\gamma M_{s}$ and $\alpha \omega=\gamma \frac{\Delta H}{2}$ ( $\omega$ is the angular frequency, $H_{i}$ is the magnetic bias field (internal field), and $\gamma$ is the gyromagnetic ratio). High frequency elec- 
tromagnetic simulations were made using HFSS software (Finite Elements Method). The real and imaginary parts of the permeability tensor are shown in figure 1 for a 139 $k A / m$ saturation magnetization and a 0.05 damping factor . Figure 1 shows the theoretical curve of $\mu$ and $\kappa$ versus frequency for a fixed applied field $(223 \mathrm{kA} / \mathrm{m})$. In the resonance frequency band, losses are high, so the component should not work in this frequency range.

\subsection{Design of coplanar isolator}

1.1. Microstrip line, slot line and coplanar line on a ferrite substrate are usable as microwave transmission lines.
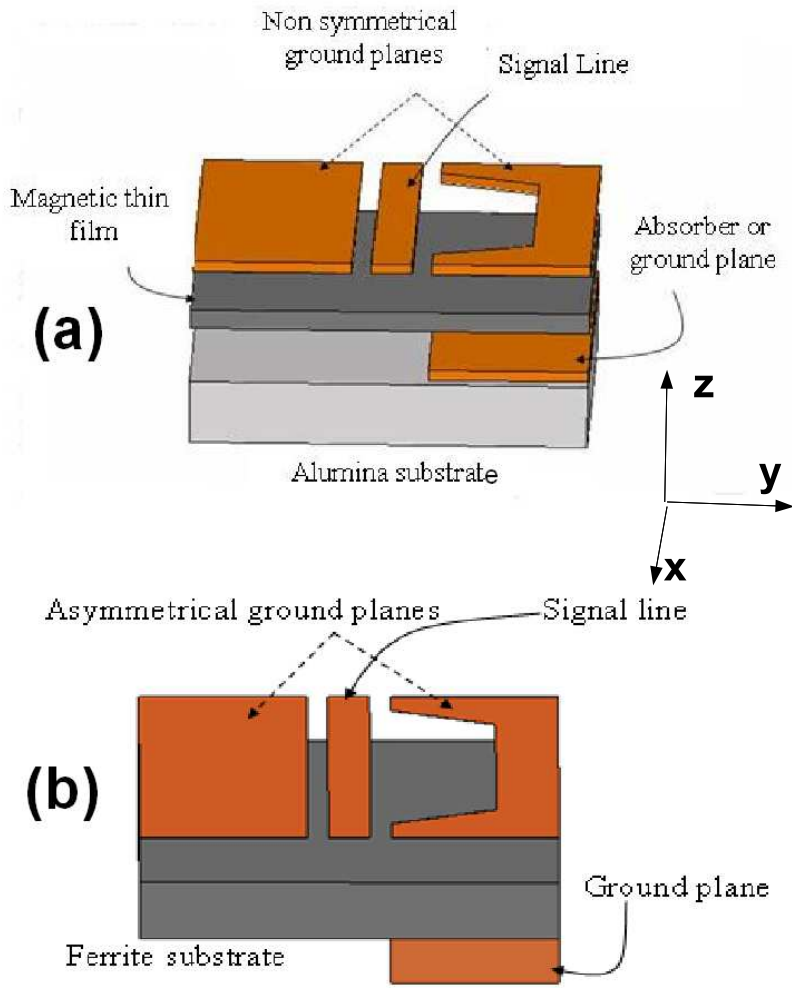

Fig. 2. Coplanar isolator structure (a) YIG layer on alumina substrate, (b) only YIG substrate
Moreover, coplanar transmission line (or coplanar waveguide CPW) can produce a non-reciprocal effect which has been already studied [6], [7]. The process of making and the interconnections between coplanar structures can make easier. The proposed isolator structure is shown in figure 2. It is made up of an asymmetrical transmission line on a ferrite substrate and a ground plane located under the ferrite layer on the side of the asymmetrical slot. When the ferrite is polarized along Z-axis, the electromagnetic field moves to one side of the line according to the propagation direction. Moreover, in this configuration, magnetostatic waves can appear and can absorb the microwave signal.

The isolator is made up of two matched ports (50 $\Omega$ ). The signal line and the non symmetrical grounds are placed in the same level on the $150 \mu m$-thick YIG layer (hf). This magnetic layer is put on a $635 \mu \mathrm{m}$-thick alumina substrate (hal). The absorber or the lower non-connected ground plane is located between the ferrite and the dielectric substrate (see Figure 2). On the other hand, first samples were made using a YIG substrate (Figure 2(b)). As previously shown, the signal line and the non symmetrical ground plane of the CPW are placed on the same plane on the YIG substrate $(1000 \mu m$ thick(hf)). The absorber or the lower non-connected ground plane is located under the ferrite substrate.

\subsection{Simulation results}

The dimensions of the asymmetrical coplanar waveguide (ACPW) (figure 3) allow to keep a quasi-TEM propagation mode [8], [9]: The asymmetric coplanar waveguide is 


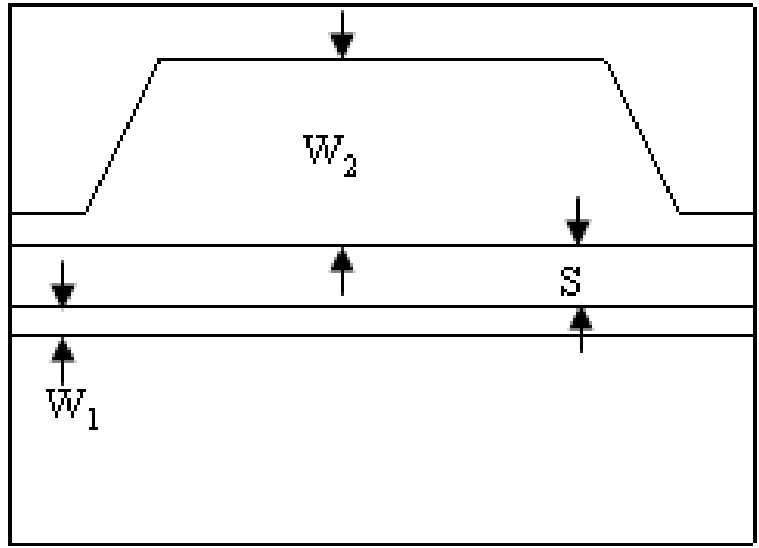

Fig. 3. Coplanar isolator structure: top view and dimensions tapered linearly to guarantee smooth transition. Also the field match should be sustained without to much introducing impedance mismatch. Some authors, for example in reference [10] where a CPW-CPS (Coplanar strip) transition is studied, show this kind of transition allows to keep quasi-TEM propagation in relative high frequency band.

- signal line: $s=400 \mu m$

- slot width: $w_{1}=200 \mu m$

- slot width (asymmetric) : $w_{2}=1200 \mu m$

- Thickness of magnetic layer: $h f=150 \mu m$ or substrate

$$
h f=1000 \mu m
$$

- structure length: $10 \mathrm{~mm}$.

A taper can be added for impedance matching (50 $\Omega$ ). Simulation results, computed on YIG substrate structure (1000 $\mu m$ thick), are given in figure 4 .

The transmission parameter curves $\left(S_{21}\right.$ and $\left.S_{12}\right)$ show high losses in the gyromagnetic frequency band between 6 and $7.8 \mathrm{GHz}\left(f_{r}=\gamma \mu_{0} H_{i}\right)$. In this configuration (D.C. field is applied along z-axis), non reciprocal propagation

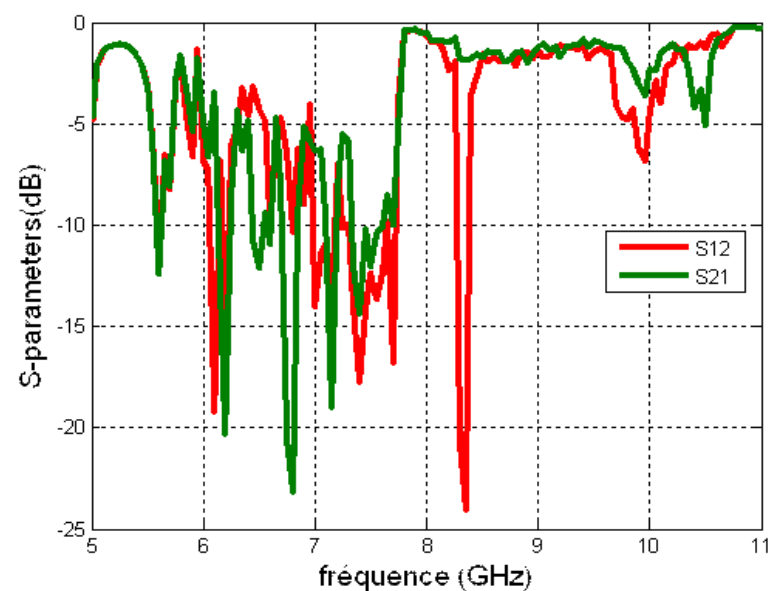

Fig. 4. Simulation results on YIG substrate structure (1000 $\mu m$ thick)

clearly appears close to $8.3 \mathrm{GHz}$. Isolation reaches more than $20 d B$ while the insertion losses remain lower than $2 d B$. However, small effects exist in the higher frequency band (close to $9-10 \mathrm{GHz}$ ). This non-reciprocal effect requires the presence of the low ground plane on one side but disappears when it is removed. This effect is not due to gyromagnetic resonance but seems be created by magneto static waves that are not properly taken into account by the software. As a matter of fact, the approximation is termed "magnetostatic" wave because the $\nabla \times \mathbf{h}=\mathbf{0}$ condition is usually valid in low frequencies, relative to the light frequency, for a given wave number k. The software HFSS is designed to solve electromagnetic and propagation problems using Maxwell equations and Polder model for magnetic materials. In the magnetostatic wave problem, the coupling between electric and magnetic fields is small. That could explained the low accuracy of the software in this configuration. However, better results are ob- 
tained when the surface of the excitation ports are modified and when the mesh size is increased. Simulation results given in figure 4 were obtained after mesh resizing and with a better port configuration.

\section{Experimental}

The $150 \mu m$-thick ferrite layer is obtained by thinning a bulk substrate. Grinding and polishing are made in order to reduce the roughness of the surface. Then, the ferrite film is put on an alumina substrate (635 $\mu m$-thick). The thickness of the copper signal Line and the ground planes is around $5 \mu \mathrm{m}$. This metal layer is deposited on the YIG ferrite layer using a lift-off process.

The other prototype (Figure 7) is made from a ferrite substrate (1000 $\mu m$-thick). Both the substrate sides are polished to reduce the roughness and to make the deposition of the copper signal line and ground planes easier(see picture in Figure 5). Then, these prototypes are characterized by using a vector network analyzer to measure Sparameters. The magnetic bias field is produced by permanent magnets and is applied during the S-parameters measurement.

The S-parameters are given in figure 6 . The gyromagnetic resonance appears is the $5.5-10 \mathrm{GHz}$ band as predicted by simulations and theory [11]. We can also observe another absorption peak of about $17 \mathrm{~dB}$ at 10.6 $G H z$ in a single propagation direction. So, an important non-reciprocal effect with insertion loss about $1 \mathrm{~dB}$ and isolation about $17 \mathrm{~dB}$ is obtained at this frequency. That special narrow peak corresponds to an isolator behavior

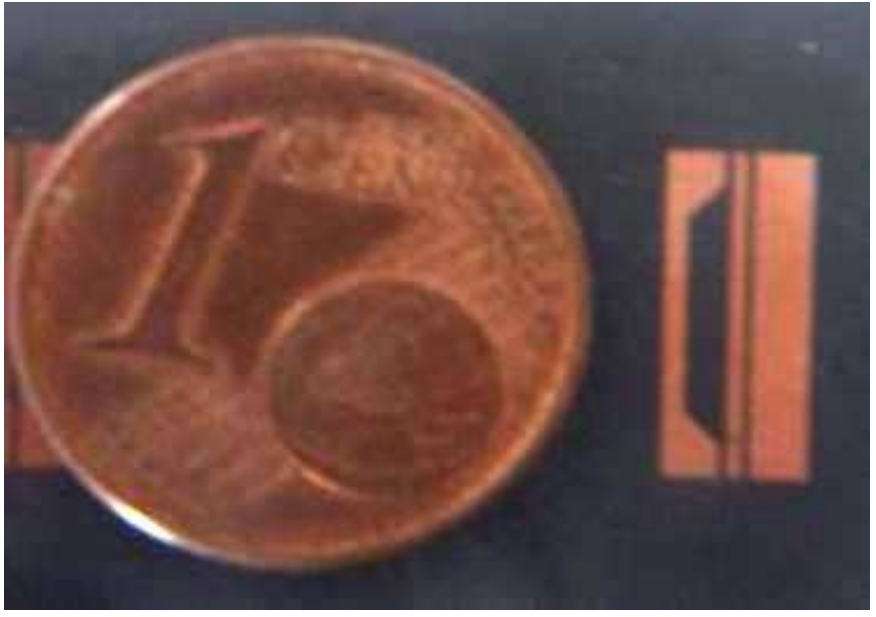

Fig. 5. picture of a prototype

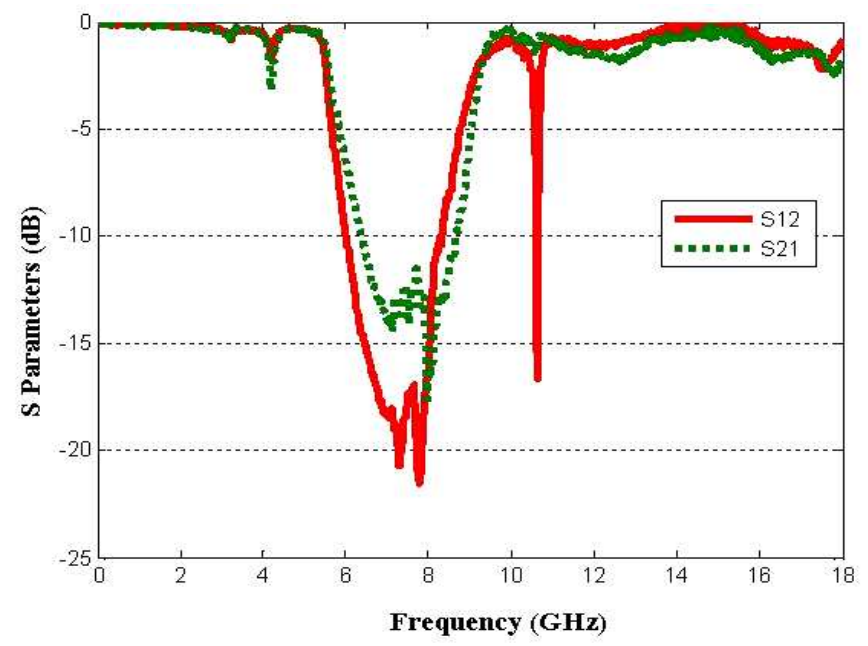

Fig. 6. Experimental results on bulk ferrite substrate $(1000$ $\mu m$ thick) prototype

with high performance. This phenomenon can be used to design an novel isolator made from an asymmetric coplanar structure. This result seems to be due to the field displacement phenomenon and unidirectional magnetostatic waves that can exist in this configuration. [12] [13]. The frequency bandwidth where ground-guided magnetostatic 
waves (MSSW) can appear, is given by [14] :

$$
\gamma \sqrt{\mathrm{H}_{0}\left(\mathrm{H}_{0}+M_{s}\right)} \leq f \leq \gamma\left(\mathrm{H}_{0}+M_{s}\right)
$$

In our case, the theoretical band is $10.03 \leq f \leq 12.82$ $G H z$. The experimental peak inside this band tends to confirm the presence of MSSWs .

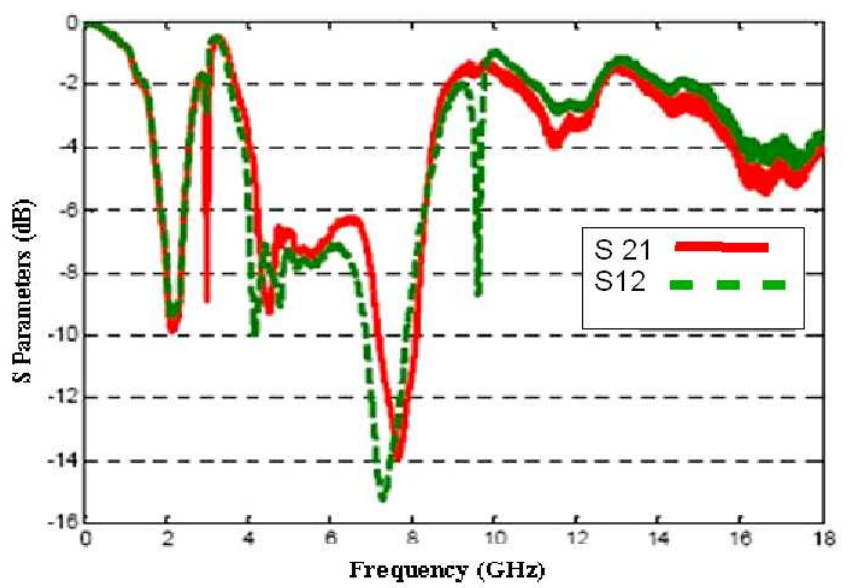

Fig. 7. Experimental results on ferrite layer (150 $\mu \mathrm{m}$ thick) prototype

In the other structure made from ferrite layer (150 $\mu m$-thick), experimental results (figure 7) also give an absorption peak of about $9.5 \mathrm{~dB}$ isolation at $10 \mathrm{GHz}$ in a single propagation direction. An important non-reciprocal effect with $1.5 d B$ insertion loss is observed. The lower ferrite thickness slightly changes the narrow peak frequency (9.9 GHz instead of $10.6 \mathrm{GHZ}$ ). The discrepancy between the frequency peaks (simulation and experimental) could be due to a deviation of the internal field (which is not perfectly known) and the (real and theoretical) values of the permeability tensor. The global effect is exactly the same even if the performance is (although not dramatically) damaged.

\section{Conclusion}

We have presented a new design of a coplanar isolator that uses the displacement field phenomenon and magnetostatic waves absorption in YIG ferrite material layer or substrate. The simulation results are obtained from Ansoft HFSS software that does not correctly take into account MMSW propagation in our structure. Measurement results are in good agreement to predict the gyromagnetic frequency band but show a special non-reciprocal peak outside. This narrow peak exists in a single propagation direction. This fundamental behavior will allow us to design a coplanar narrow band isolator. Further works will optimize the performance. Dimensions, applied field, material properties etc... must be defined to increase the isolation level, to reduce the insertion loss and to broaden the bandwidth. Moreover, this first study has shown that the thinning of the ferrite film is possible without too much damaged performance. These promising prototypes could constitute new integrated isolators in telecommunication systems.

\section{References}

1. S. Capraro, T. Rouiller, M. L. berre, J. P. Chatelon, B. Bayard, D. Barbier, and J. J. Rousseau, "Feasibility of a self biased coplanar isolator with barium ferrite films," IEEE 
Transactions on Components and Packaging technologies, vol. 30, no. 3, pp. 411-415, September 2007.

2. isolator based on thin magnetic films," Microwave and optical technology letters, vol. 46, no. 5, pp. 435-437, September 2005 .

3. M. Hines, "Reciprocal and nonreciprocal modes of propagation in ferrite stripline and microstrip devices," IEEE Trans. Microwave Theory Tech., vol. 19, no. 5, pp. 442451, 1971.

4. C. P. Wen, "Coplanar waveguide: A surface strip transmission line suitable for nonreciprocal gyromagnetic device application," IEEE Trans. on micowave Theory and tech., vol. MTT-17, no. 12, 1969.

5. D. Polder, "On the theory of ferromagnetic resonance," Philos.Mag., vol. 40, p. 99, January 1949.

6. J. Borburgh, "The behaviour of guided mode on ferritefilled microstrip line with the magnetization perpendicular to the ground plane," Arch Elec Ubertrafungs, vol. 31, pp. 73-77, 1977.

7. B. Bayard, D. Didier, C. Simovski, and G. Noyel, "Electromagnetic study of a ferrite coplanar isolator suitable for integration," IEEE MTT Trans. Microwave Theory Tech., vol. 51, no. N 7, pp. 1809-1814, July 2003.

8. W. Heinrich, "Quasi-tem description of mmic coplanar lines including conductor-loss effects," IEEE Trans on Microwave Theory and Thechniques, vol. 41, no. 1, 1993.

9. T. Kitazawa and R. Mittra, "Quasi-static characteristics of asymmetrical and coupled coplanar-type transmission lines," IEEE Transactions on Microwave Theory and Techniques, vol. 33, no. 9, pp. $771-778$, January 2003.
10. S.-G. Mao, C.-T. Hwang, R.-B. Wu, and C. H. Chen, "Analysis of coplanar waveguide-to-coplanar stripline transitions," IEEE TRANSACTIONS ON MICROWAVE THEORY AND TECHNIQUES, vol. 48, no. 1, pp. 23-29, JANUARY 2000.

11. C. Kittel, Introduction to Solid State Physics, second edition (french), Ed. Dunod Paris, 1970.

12. M. Tsutsami, K. Kikui, and Ueda, "Characteristics of slot line yittrium iron garnet substrate and its application," in Proceeding of APMC Taipei Taiwan R. O. C., 2001.

13. M. Tsutsumi and T. Asahara, "Microstrip lines using yttrium iron garnet film," IEEE MTT Trans. Microwave Theory Tech., vol. 38, no. 10, pp. 1461-1467, October 1990.

14. H. V. D. Vaart, "Influence of metal plate on surface magnetostatic modes of magnetic slab," Electron. Lett., vol. 6, no. 19 , p. 601602,17 september 1970. 